\title{
System-Like Consolidation of Olfactory Memories in Drosophila
}

\author{
Isaac Cervantes-Sandoval, Alfonso Martin-Peña, Jacob A. Berry, and Ronald L. Davis \\ Department of Neuroscience, The Scripps Research Institute Florida, Jupiter, Florida 33410
}

System consolidation, as opposed to cellular consolidation, is defined as the relatively slow process of reorganizing the brain circuits that maintain long-term memory. This concept is founded in part on observations made in mammals that recently formed memories become progressively independent of brain regions initially involved in their acquisition and retrieval and dependent on other brain regions for their long-term storage. Here we present evidence that olfactory appetitive and aversive memories in Drosophila evolve using a systemlike consolidation process. We show that all three classes of mushroom body neurons (MBNs) are involved in the retrieval of short- and intermediate-term memory. With the passage of time, memory retrieval becomes independent of $\alpha^{\prime} / \beta^{\prime}$ and $\gamma$ MBNs, and long-term memory becomes completely dependent on $\alpha / \beta$ MBNs. This shift in neuronal dependency for behavioral performance is paralleled by shifts in the activity of the relevant neurons during the retrieval of short-term versus long-term memories. Moreover, transient neuron inactivation experiments using flies trained to have both early and remote memories showed that the $\alpha^{\prime} / \beta^{\prime}$ MBNs have a time-limited role in memory processing. These results argue that system consolidation is not a unique feature of the mammalian brain and memory systems, but rather a general and conserved feature of how different temporal memories are encoded from relatively simple to complex brains.

\section{Introduction}

Memories, shortly after they are acquired, are labile and susceptible to disruption by factors such as interference information, injuries, or amnesiac agents (Scoville and Milner, 1957; McGaugh and Alpern, 1966; Squire et al., 1975; Quinn and Dudai, 1976). If acquisition signals are sufficiently strong, often produced by spaced training (Carew et al., 1972; Tully et al., 1994), memories mature, become resilient to these insults, and endure in a long-lasting form. The process of progressive stabilization is referred to as memory consolidation, which consists of at least two mechanistically and temporally different forms: (1) cellular consolidation, which is relatively fast and requires cell signaling within the local nodes or individual neurons of the brain; and (2) system consolidation, which is slow and involves communication between neurons in different regions of the brain, the reorganization of brain circuits, and the relocation of the traces that represent the memory (Dudai, 2004; Frankland and Bontempi, 2005). The standard model for system consolidation in mammals (Dudai, 2004) envisions initial memories being encoded in the medial temporal lobe system and relevant areas of the neocortex, with subsequent reorganization of circuits and memory traces

\footnotetext{
Received Jan. 30, 2013; revised May 2, 2013; accepted May 2, 2013.

Author contributions: I.C.-S., A.M.-P., J.A.B., and R.L.D. designed research; I.C.-S., A.M.-P., and J.A.B. performed research; I.C.-S. and R.L.D. analyzed data; I.C.-S. and R.L.D. wrote the paper.

This research was supported by the National Institutes of Health (Grant \#NS05235 to R.L.D.).

The authors declare no competing financial interests.

Correspondence should be addressed to either Isaac Cervantes-Sandoval or Ronald L. Davis, Department of

Neuroscience, The Scripps Research Institute Florida, 130 Scripps Way C349, Jupiter, FL 33410. E-mail: isandova@scripps.edu or rdavis@scripps.edu.

DOI:10.1523/JNEUROSCI.0451-13.2013

Copyright $\odot 2013$ the authors $\quad 0270-6474 / 13 / 339846-09 \$ 15.00 / 0$
}

such that the neocortex assumes the burden of storing long-term memory (LTM)

The concept of system consolidation was founded in several seminal observations. First, humans with lesions limited to the medial temporal lobe display temporally graded retrograde amnesia (Scoville and Milner, 1957), with recent memories being abolished and remote memories being spared (Kapur and Brooks, 1999; Manns et al., 2003). Second, selective lesions to the hippocampal formation or entorhinal cortex of laboratory animals produce a similar, temporally graded amnesia (ZolaMorgan and Squire, 1990; Cho et al., 1993; Clark et al., 2002). In contrast, pharmacological inactivation of cortical regions disrupts remote but not early memories (Frankland et al., 2004; Maviel et al., 2004). Finally, functional imaging experiments have provided a critical and defining feature of system consolidation. The retrieval of recent memories preferentially activates neurons in the hippocampus but not the cortical regions tested, whereas the retrieval of remote memories activates these cortical regions but not hippocampal regions (Bontempi et al., 1999; Frankland et al., 2004; Maviel et al., 2004; Frankland and Bontempi, 2005).

Several lines of evidence are consistent with the hypothesis that olfactory memories generated by classical conditioning of Drosophila undergo system consolidation (see Discussion). Here, we offer a complete set of data consistent with the hypothesis that both aversive and appetitive olfactory memories in Drosophila are processed in a system-consolidation-like manner. Most importantly, we have modeled our studies from the standards used to define system consolidation in mammalian organisms.

\section{Materials and Methods}

Fly lines. Flies (Drosophila melanogaster) carrying uas transgenes included: (1) uas-shi ${ }^{\text {ts }}$, containing one copy on the X-chromosome and two 
Table 1. Olfactory avoidance for all genotypes used in this study

\begin{tabular}{|c|c|c|c|c|c|c|c|c|}
\hline & \multicolumn{2}{|l|}{ 0ct } & \multicolumn{2}{|l|}{ Mch } & \multicolumn{2}{|l|}{ Ben } & \multicolumn{2}{|l|}{ Mes } \\
\hline & $24^{\circ} \mathrm{C}$ & $32^{\circ} \mathrm{C}$ & $24^{\circ} \mathrm{C}$ & $32^{\circ} \mathrm{C}$ & $24^{\circ} \mathrm{C}$ & $32^{\circ} \mathrm{C}$ & $24^{\circ} \mathrm{C}$ & $32^{\circ} \mathrm{C}$ \\
\hline c305a-gal4/uas-shits & $0.63 \pm 0.08$ & $0.67 \pm 0.06$ & $0.82 \pm 0.07$ & $0.79 \pm 0.09$ & $0.89 \pm 0.04$ & $0.84 \pm 0.12$ & $0.56 \pm 0.05$ & $0.60 \pm 0.04$ \\
\hline 1471-gal4/uas-shits & $0.73 \pm 0.09$ & $0.71 \pm 0.07$ & $0.90 \pm 0.04$ & $0.92 \pm 0.1$ & $0.81 \pm 0.04$ & $0.81 \pm 0.03$ & $0.55 \pm 0.04$ & $0.60 \pm 0.1$ \\
\hline c739-gal4/uas-shits & $0.71 \pm 0.04$ & $0.70 \pm 0.03$ & $0.97 \pm 0.07$ & $0.95 \pm 0.03$ & $0.76 \pm 0.05$ & $0.74 \pm 0.06$ & $0.69 \pm 0.08$ & $0.71 \pm 0.09$ \\
\hline \multirow[t]{2}{*}{ 247-gal4/uas-shits } & $0.54 \pm 0.08$ & $0.57 \pm 0.04$ & $0.69 \pm 0.07$ & $0.71 \pm 0.11$ & ND & ND & ND & ND \\
\hline & $24^{\circ} \mathrm{C}$ & $30^{\circ} \mathrm{C}$ & $24^{\circ} \mathrm{C}$ & $30^{\circ} \mathrm{C}$ & $24^{\circ} \mathrm{C}$ & $30^{\circ} \mathrm{C}$ & $24^{\circ} \mathrm{C}$ & $30^{\circ} \mathrm{C}$ \\
\hline c305a-gal4/uas-kir2.1;tub-gal80 ts & $0.65 \pm 0.04$ & $0.69 \pm 0.08$ & $0.79 \pm 0.04$ & $0.77 \pm 0.05$ & $0.93 \pm 0.03$ & $0.87 \pm 0.1$ & $0.71 \pm 0.05$ & $0.69 \pm 0.08$ \\
\hline
\end{tabular}

No significant difference was found at different temperatures for any genotype tested. For flies of the genotype c $305 a$-gal $4 /$ uas-kir2.1; tub-gal $80^{\text {ts }}$, the avoidance was tested at $24^{\circ} \mathrm{C}$ and compared to avoid flies subjected to a pretreatment of $6 \mathrm{~h}$ at $30^{\circ} \mathrm{C}$.

copies on the third chromosome (Kitamoto, 2001), (2) uas-G-CaMP3.0 (Tian et al., 2009), and (3) two lines containing a uas-kir2.1 insertion on the second or third chromosome (Baines et al., 2001). Gal4 driver lines included c305a-gal4, c739-gal4, 1471-gal4, and 247-gal4. Numerous groups have characterized the expression patterns for these lines, but a single-source reference can be found in Aso et al. (2009). In addition, the line $228 H 05$-gal4 was used as an alternative $\alpha / \beta \mathrm{MBN}$ driver (Jenett et al., 2012). Finally, tub-gal80 ${ }^{\text {ts }}$ was used in TARGET experiments (McGuire et al., 2003).

Behavioral conditioning. For aversive and appetitive training, flies were conditioned behaviorally using a standard, two-odor discriminative and negatively or positively reinforced classical-conditioning paradigm (Tempel et al., 1983; Tully and Quinn, 1985). For appetitive conditioning, flies were starved for $16-24 \mathrm{~h}$ in vials containing $0.8 \%$ non-nutritive agar. Groups of $\sim 60$ flies were then exposed to conditioned stimulus $(\mathrm{CS})^{-}$odor with a dry filter paper previously saturated with water for 2 min, followed by $30 \mathrm{~s}$ of air and then $2 \mathrm{~min}$ of $\mathrm{CS}^{+}$odor together with a dried filter paper previously saturated with $2 \mathrm{M}$ sucrose. This order in the odor presentation was performed to avoid any possible contamination of sucrose on the legs of flies that could become associated with the $\mathrm{CS}^{-}$ odor. For aversive conditioning, flies were exposed to $1 \mathrm{~min}$ of $\mathrm{CS}^{+}$odor together with 12 electric shocks $(90 \mathrm{~V}, 1.5 \mathrm{~s})$ followed by $30 \mathrm{~s}$ of air and 1 min of the $\mathrm{CS}^{-}$odor. Table 1 shows olfactory avoidance for all genotypes used in this study.

Functional imaging. Functional cellular imaging was performed as described previously (Yu et al., 2005; Cervantes-Sandoval and Davis, 2012). Flies were prepared for functional imaging either 1 or $24 \mathrm{~h}$ after conditioning. Flies were mounted in pipette tips and their exposed heads were secured to the tip opening using melted myristic acid. A small area of the cuticle was removed from the top of the head capsule and the opening was covered with a piece of plastic wrap. The flies were then mounted beneath a $20 \times$ objective of a Leica TCS confocal microscope and imaged with a $488 \mathrm{~nm}$ excitation line. The emitted light was collected from $520 \pm$ $15 \mathrm{~nm}$. Odors were delivered with pressurized air flowing at a rate of 200 $\mathrm{ml} / \mathrm{min}$. Odorants were diluted 1:10 with mineral oil and spread on a 1 $\mathrm{cm}^{2}$ filter paper inside a scintillation vial and in line with the pressurized air. The delivery of odorants was accomplished with a three-way Teflon valve under the control of a programmable timer such that fresh air could be delivered to the animals for a determined period with an instantaneous switch to odor-laced air without altering the overall flow rate. Each fly was used only once to avoid odor habituation, adaptation, sensitization, or generalization.

Images were acquired at 5 frames/s at a resolution of $256 \times 256$ pixels. The image data were analyzed as described previously (Yu et al., 2005). In general, xyt imaging stacks were obtained and regions of interest circumscribed. The value of $F_{\mathrm{o}}$ was calculated for each pixel within the region of interest as the fluorescence before odor application as averaged over five successive frames. The value of $\Delta F$ was calculated for each pixel within the region of interest as the difference between the maximum average intensity during $3 \mathrm{~s}$ of odor application for five successive frames and $F_{\mathrm{o}}$ (Yu et al., 2005; Yu et al., 2006). Imaging data are presented as the ratio of the response to the $\mathrm{CS}^{+}\left(\Delta F / F_{\mathrm{o}}\right)$ to the $\mathrm{CS}^{-}\left(\Delta F / F_{\mathrm{o}}\right)$ (CervantesSandoval and Davis, 2012). Statistical significance was determined using two-way ANOVA followed by pairwise nonparametric Mann-Whitney comparisons.

\section{Results}

\section{Disrupting different MBNs impairs retrieval of different temporal phases of appetitive and aversive olfactory memories}

To determine which candidate regions of the Drosophila brain are required for retrieval of recent versus remote memories, we first probed whether retrieval processes required intact synaptic function of the three classes of MBNs at six different times after appetitive olfactory conditioning. Prior characterization of appetitive memory in Drosophila revealed that a single training session generates memory that lasts for days, with the memory becoming dependent on protein synthesis by $6 \mathrm{~h}$ after conditioning (Krashes and Waddell, 2008; Colomb et al., 2009). We used $s h i^{\text {ts }}$, a temperature-sensitive and dominant-negative version of dynamin, to impose a synaptic blockade during the test for memory performance. Flies containing a specific MBNs gal4 driver (c305a-gal4, 1471-gal4, c739-gal4, or 247-gal4 for $\alpha^{\prime} \beta^{\prime}, \gamma, \alpha \beta$, and $\alpha \beta \gamma$, respectively) and the uas-shi $i^{\text {ts }}$ transgene were trained at $24^{\circ} \mathrm{C}$ and shifted to $32^{\circ} \mathrm{C} 10 \mathrm{~min}$ before and during testing at different posttraining time points. Control flies containing only the gal4 driver or the uas-shi ${ }^{\text {ts }}$ transgene showed no decrease in memory performance, but combining the two elements to block synaptic output from $\alpha^{\prime} / \beta^{\prime}$ MBNs completely impaired memory retrieval from $15 \mathrm{~min}$ to $3 \mathrm{~h}$ after appetitive conditioning (Fig. $1 A$ ). A prior study suggested that appetitive memory retrieval was independent of $\alpha^{\prime} / \beta^{\prime}$ MBNs output tested at $2 \mathrm{~h}$ (Trannoy et al., 2011). This conflicting result may be explained by the use of different versions of the uas-shi ${ }^{\text {ts }}$ transgene and/or assay insensitivity in the prior study revealed by low performance indices for control flies $(\sim 0.2)$ compared with the $\sim 0.4$ obtained here. Moreover, testing at four sequential time points, as performed here, offers greater reliability than the single time point tested previously (Trannoy et al., 2011). Sugar responsiveness has been shown previously to be normal in the genotypes tested here (Krashes and Waddell, 2008; Trannoy et al., 2011).

Memory expression was also blocked after aversive conditioning from $15 \mathrm{~min}$ to $1.5 \mathrm{~h}$ after training, with expression becoming independent of $\alpha^{\prime} / \beta^{\prime}$ MBN blockade by $3 \mathrm{~h}$ (Fig. $2 A$ ), which is consistent with other studies (Krashes et al., 2007). Aversive olfactory memory generated by a single training session decays to near zero by $24 \mathrm{~h}$ and is independent of protein synthesis. Therefore, spaced training was used to generate protein synthesisdependent $24 \mathrm{~h}$ LTM after aversive training (Tully et al., 1994). Blocking the output of $\alpha^{\prime} / \beta^{\prime}$ MBNs had no effect on the retrieval of $24 \mathrm{~h}$ protein-synthesis-dependent LTM (Fig. 2A). These data indicate that memory retrieval is dependent on the synaptic output of the $\alpha^{\prime} / \beta^{\prime}$ MBNs to at least $3 \mathrm{~h}$ for appetitive memories and at least $1.5 \mathrm{~h}$ for aversive memories. It then becomes independent of neurotransmission from these neurons. 


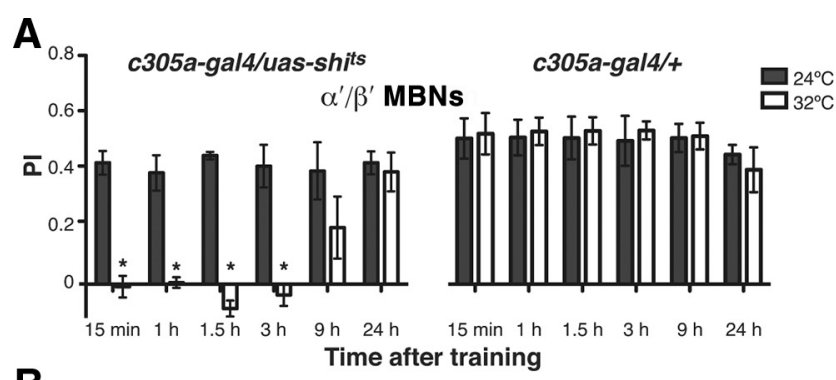

B

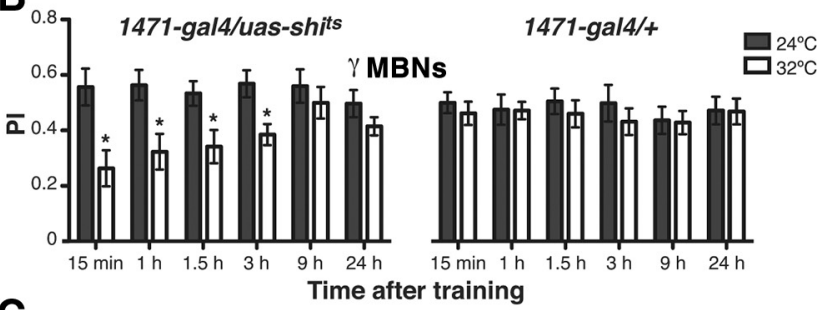

C

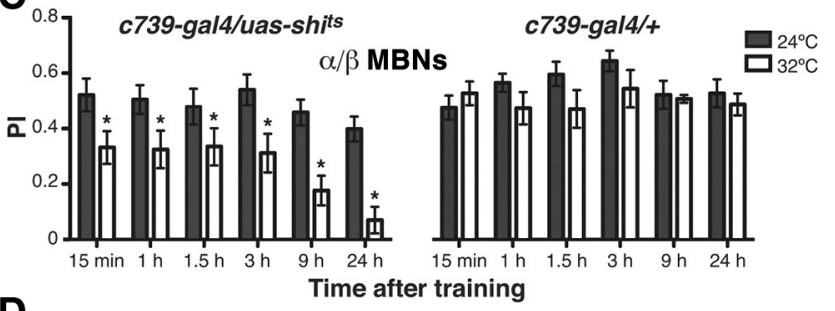

D
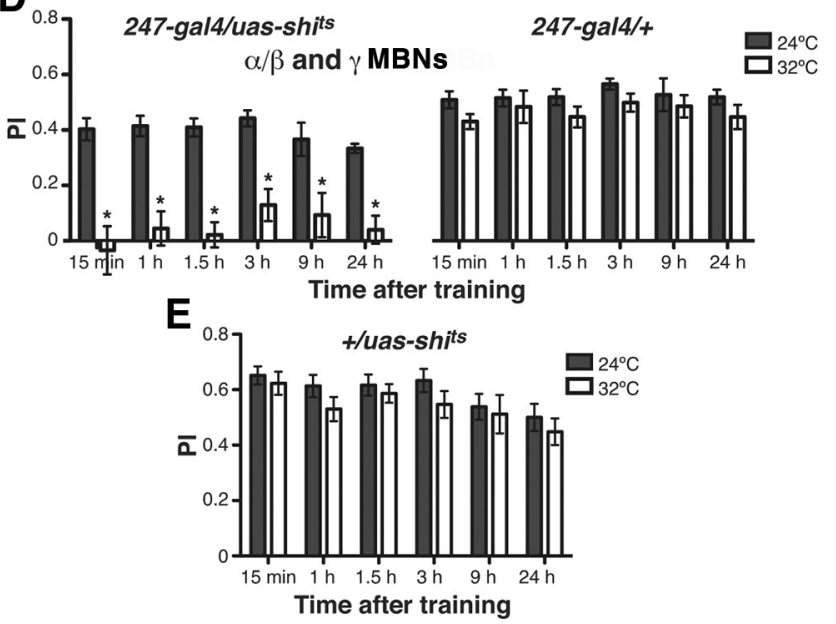

Figure 1. Time requirements for synaptic output from MBN subsets for the retrieval of appetitive olfactory memory. $\boldsymbol{A}$, All flies were conditioned using an appetitive unconditioned stimulus at $24^{\circ} \mathrm{C}$ and shifted to $32^{\circ} \mathrm{C} 10 \mathrm{~min}$ before a retrieval test. A synaptic blockade imposed by the expression and activation of $s h{ }^{\text {ts }}$ in the $\alpha^{\prime} / \beta^{\prime}$ MBNs significantly reduced memory expression from 15 min to $3 \mathrm{~h}$ after training (Mann-Whitney pairwise comparisons, $p \leq$ 0.0022). No significant difference was observed during retrieval of memory from 9 to $24 \mathrm{~h}$ after training (Mann-Whitney pairwise comparisons, $p \geq 0.2403$ ). No significant difference was observed between permissive and restrictive temperatures for control flies carrying only the c305a-gal4 element (Mann-Whitney pairwise comparisons, $p \geq 0.5887$ ). $\boldsymbol{B}$, Synaptic blockade of $\gamma$ MBNs significantly reduced appetitive olfactory memory expression from $15 \mathrm{~min}$ to $3 \mathrm{~h}$ after training (Mann-Whitney pairwise comparisons, $p \leq 0.0411$ ). No significant difference was observed during retrieval of memory from $9 \mathrm{to} 24 \mathrm{~h}$ after training (Mann-Whitney pairwise comparisons, $p \geq 0.3315$ ). No significant difference was observed between permissive and restrictive temperatures for control flies carrying only the 1471-gal4 element (Mann-Whitney pairwise comparisons, $p \geq 0.4696)$. C, Synaptic blockade of $\alpha / \beta$ MBNs significantly reduced appetitive olfactory memory expression from $15 \mathrm{~min}$ to $24 \mathrm{~h}$ after training (Mann-Whitney pairwise comparisons, $p \leq 0.045$ ). No significant difference was observed between permissive and restrictive temperatures for control flies carrying only the c739-gal 4 element (Mann-Whitney pairwise comparisons, $p \geq 0.1727)$. $\boldsymbol{D}$, Synaptic blockade using shi ${ }^{\text {ts }}$ of $\alpha / \beta$ and $\gamma \mathrm{MBNs}$ eliminated appetitive olfactory memory expression from $15 \mathrm{~min}$ to $24 \mathrm{~h}$ after training (MannWhitney pairwise comparisons, $p \leq 0.0304$ ). The performance of 247 -gal4/uas-shi ${ }^{\text {ts }}$ flies at
Blocking neurotransmission from $\gamma \mathrm{MBNs}$ partially impaired $(\sim 30-50 \%)$ retrieval of appetitive olfactory short-term memory (STM) and intermediate-term memory (ITM; 15 min-3 h), but left LTM (9-24 h) retrieval intact (Fig. 1B). Similar results were obtained upon blocking the output of $\gamma$ MBNs after aversive training (Fig. 2B). As was the case for the $\alpha^{\prime} / \beta^{\prime}$ MBNs, these results reveal that olfactory memories in Drosophila are initially dependent on the output of $\gamma \mathrm{MBNs}$ and that they lose this dependency with time.

Finally, blocking the output of $\alpha / \beta$ MBNs impaired ( $~ 30 \%$ ) the performance of STM and ITM and completely abrogated the retrieval of LTM (Fig. 1C). Once again, similar results were obtained when we evaluated the output requirement of $\alpha / \beta \mathrm{MBNs}$ for the retrieval of aversive memories (Fig. $2 C$ ). Our results with aversively conditioned flies are in agreement with data from more limited studies (McGuire et al., 2001; Akalal et al., 2006).

A small decrement in expression of aversive memory was observed during retrieval at early time points at restrictive temperature in control flies carrying only the gal4 or uas-shit ${ }^{\text {ts }}$ elements due to heat stress (Fig. $2 A-D$ ). This nonspecific effect of heat was observed by two independent laboratory investigators collecting data for this study, occurred only at early time points $(<1.5 \mathrm{~h})$ after conditioning, was not observed after appetitive conditioning (Fig. 1), and has been observed in numerous prior studies using aversive olfactory conditioning (Waddell et al., 2000; Dubnau et al., 2001; McGuire et al., 2001; Zhang et al., 2008; Berry et al., 2012). Nevertheless, this decrement in performance was much smaller than the decrement observed in experimental flies carrying both the gal4 and uas-shits ${ }^{\text {ts }}$ transgenes.

The partial effect of blocking neurotransmission of $\alpha / \beta$ and $\gamma$ $\mathrm{MB}$ cells in the retrieval of STM/ITM led us to investigate whether the partial contribution of these neuron subsets for STM/ITM retrieval are summative, and therefore involve parallel pathways, or if they are serial, occurring in the same pathway. For this, we imposed synaptic blockade during retrieval using the 247-gal4 transgene, which drives expression in both subsets of MBNs. Complete impairment of appetitive STM/ITM and LTM was observed when $\alpha / \beta$ and $\gamma \mathrm{MBNs}$ were blocked during retrieval (Fig. $1 D)$, suggesting that these subsets contribute to memory expression in parallel pathways for the normal retrieval of STM/ITM. Shock avoidance has been shown to be normal in the genotypes tested here (Isabel et al., 2004; Krashes et al., 2007).

\section{MBNs' requirement for retrieval is independent of odor selection}

Due to previous studies showing that odors are sparsely represented in the MBNs (Wang et al., 2003; Turner et al., 2008), with different odors perhaps represented unequally by the three subtypes of MBNs, there was the possibility that the memory retrieval dependency results obtained above could be dependent on the odor combination used for conditioning (3-octanol [Oct] and 4-methylcyclohexanol [Mch]). To test this possibility, we evaluated the dependency on MBN subsets for retrieval of 1 and $24 \mathrm{~h}$ appetitive memory using a different odor combination of benzaldehyde (Ben) and methylsalicylate (Mes). Our results

restrictive temperature at all times tested was not significantly different from zero (Wilcoxon signed rank tests, $p \geq 0.0938$ ). No significant difference was observed between permissive and restrictive temperatures for control flies carrying only the 247-gal4 element (Mann-Whitney pairwise comparisons, $p \geq 0.1087$ ). $\boldsymbol{E}$, No significant difference was observed between permissive and restrictive temperatures for control flies carrying only the uas-shit ${ }^{\text {ts }}$ element (MannWhitney pairwise comparisons, $p \geq 0.0916$ ). 
A

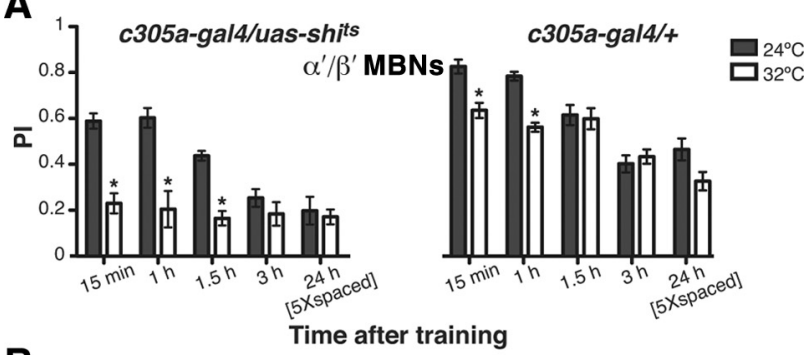

B
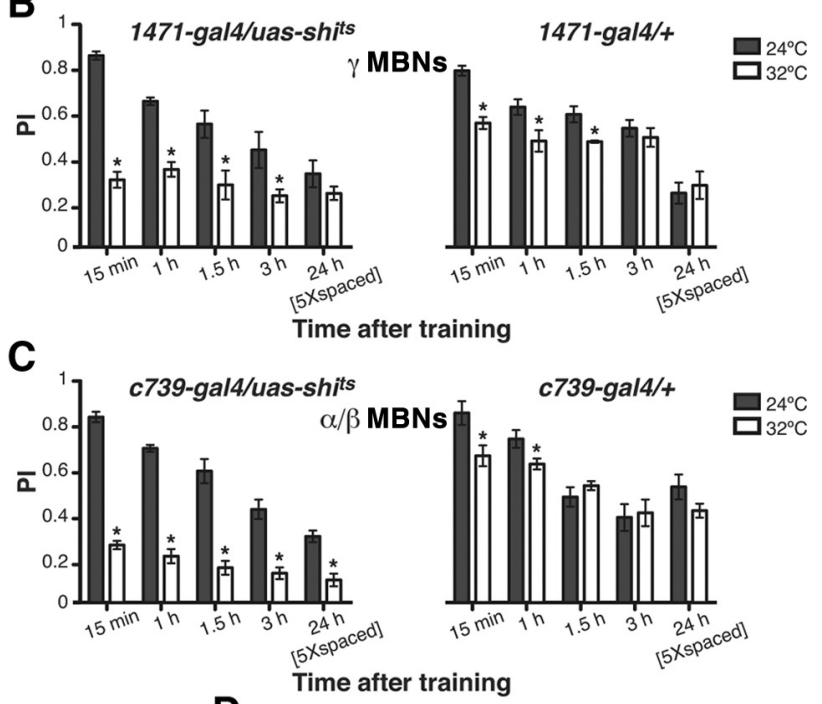

D

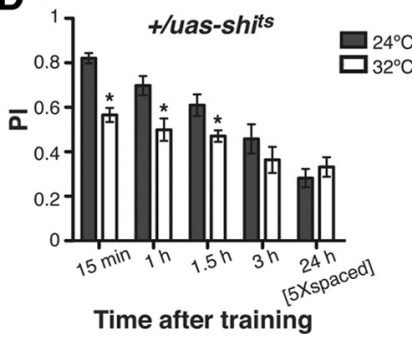

Figure 2. Time requirements for synaptic output from MBN subsets for the retrieval of aversive olfactory memory. $\boldsymbol{A}$, All flies were trained using an aversive unconditioned stimulus at $24^{\circ} \mathrm{C}$ and shifted to $32^{\circ} \mathrm{C} 10 \mathrm{~min}$ before a retrieval test. A synaptic blockade imposed by the expression and activation of shit in the $\alpha^{\prime} / \beta^{\prime}$ MBNs significantly reduced memory expression from 15 min to $1.5 \mathrm{~h}$ after training (Mann-Whitney pairwise comparisons, $p \leq 0.0043$ ). No significant difference was observed during retrieval of memory at 3 or $24 \mathrm{~h}$ after training (Mann-Whitney pairwise comparisons, $p \geq 0.4452$ ). Asmall decrement in expression of aversive memory was observed during retrieval at early time points at restrictive temperature in control flies carrying only the c305a-gal4 element (Mann-Whitney pairwise comparisons, $p \geq 0.0022$ ) due to heat stress. This decrement was not observed at subsequent time points (Mann-Whitney pairwise comparisons, $p \geq 0.0931$ ) and is discussed further in the text. $\boldsymbol{B}$, Synaptic blockade of $\gamma$ MBNs significantly reduced aversive olfactory memory expression from 15 min to $3 \mathrm{~h}$ after training (Mann-Whitney pairwise comparisons, $p \leq$ 0.0260). No significant difference was observed during retrieval of memory at $24 \mathrm{~h}$ after training (Mann-Whitney pairwise comparison, $p=0.4286$ ). A small decrement in performance of aversive memory was observed during retrieval of 15 min to $1.5 \mathrm{~h}$ memory at restrictive temperature in control flies carrying only the 1471-gal4 element (Mann-Whitney pairwise comparisons, $p \geq 0.0152$ ). This impairment was not observed at subsequent time points (Mann-Whitney pairwise comparisons, $p \geq 0.6623$ ). C, Synaptic blockade of $\alpha / \beta$ MBNs significantly reduced aversive olfactory memory expression from 15 min to $24 \mathrm{~h}$ after training (Mann-Whitney pairwise comparisons, $p \leq 0.0095$ ). A small decrement in performance of aversive memory was observed during retrieval at $15 \mathrm{~min}$ and $1 \mathrm{~h}$ at restrictive temperature in control flies carrying only the 7339 -gal4 element (Mann-Whitney pairwise comparisons, $p \geq 0.0411)$. This impairment was not observed at subsequent time points (Mann-Whitney pairwise comparison, $p \geq 0.1320$ ). $\boldsymbol{D}$, A slight decrement in performance of aversive memory expression was observed during retrieval from $15 \mathrm{~min}$ to $1.5 \mathrm{~h}$ at restrictive temperature in control flies carrying only the uas-sh ${ }^{\text {ts }}$ genetic element (Mann-Whitney pairwise comparison, $p \geq 0.0303$ ). This impairment was not observed at subsequent time points (Mann-Whitney pairwise comparison, $p \geq 0.3095$ ). showed a similar dependency on synaptic transmission from the various classes of MBNs for the retrieval of olfactory memories. Synaptic blockade of $\alpha^{\prime} / \beta^{\prime}$ and $\gamma$ MBNs disrupted $1 \mathrm{~h}$, but not $24 \mathrm{~h}$, memory, whereas blocking $\alpha / \beta$ MBNs compromised $1 \mathrm{~h}$ memory and completely abolished LTM at $24 \mathrm{~h}$ (Fig. 3).

These results indicate that olfactory memory retrieval is initially dependent on synaptic transmission of all three subsets of MBNs. With maturation of the memory engram, the dependence on $\alpha^{\prime} / \beta^{\prime}$ and $\gamma$ MBNs wanes and retrieval becomes completely dependent on synaptic transmission from the $\alpha / \beta$ MBNs. This shift in dependence suggests that olfactory memory processing in Drosophila is analogous to how memories are processed in mammals. Spatial and declarative memories are initially encoded in both hippocampal and cortical systems, which then undergo circuit reorganization, leading to the loss of dependency on the hippocampal system and the complete dependence on the cortical network (Dudai, 2004).

\section{Retrieval of recent and remote memories activates different subsets of MBNs}

Imaging studies in mammals using 2-deoxyglucose mapping or immediate-early gene activation have revealed that the retrieval of recent and remote memories activates different brain regions. The recall of recent spatial or contextual fear memories is associated with activation of the hippocampus and entorhinal cortex. In contrast, the recall of remote spatial memories is predominantly associated with the activation of cortical regions (Bontempi et al., 1999; Frankland et al., 2004; Maviel et al., 2004). We have previously used functional cellular imaging in living flies to show that odor evoked calcium responses in the $\alpha / \beta$ MBNs to the learned odor increase at $9 \mathrm{~h}$ after aversive conditioning. This enhancement persists through $24 \mathrm{~h}$ and requires normal protein synthesis, spaced conditioning, the activity of the transcription factor Creb, and the normal function of 26 different LTM genes (Yu et al., 2006; Akalal et al., 2011). A similar enhanced response to the learned odor occurs in the $\alpha^{\prime} / \beta^{\prime}$ MBNs at $1 \mathrm{~h}$ after single cycle aversive conditioning (Wang et al., 2008). We therefore quantitated the $\mathrm{Ca}^{2+}$ responses using G-CaMP 3.0 (Tian et al., 2009 ) in the vertical lobes of $\alpha^{\prime} / \beta^{\prime}$ and $\alpha / \beta$ MBNs upon retrieval of appetitive STM/ITM $(1 \mathrm{~h})$ and LTM $(24 \mathrm{~h})$. We used the ratio of the response of the $\mathrm{CS}^{+}$and $\mathrm{CS}^{-}$odor within each individual fly to quantitate the change in response to the learned odor (Cervantes-Sandoval and Davis, 2012).

As with aversive conditioning, we detected an increased response in the vertical branch of $\alpha^{\prime} / \beta^{\prime}$ MBNs upon presenting the retrieval cue $1 \mathrm{~h}$ after appetitive conditioning, but not at $24 \mathrm{~h}$ (Fig. $4 A)$. Naive flies and flies trained with unpaired appetitive conditioning (Fig. $4 A$ and data not shown) exhibited no selective increase in the response to the $\mathrm{CS}^{+}$. This is an important observation in itself, showing that the $\alpha^{\prime} / \beta^{\prime}$ MBNs form a timelimited memory trace with both aversive and appetitive conditioning shortly after conditioning. We also detected an increased response in the vertical branch of the $\alpha / \beta$ MBNs upon presenting the retrieval cue at $24 \mathrm{~h}$ after appetitive conditioning, but not at $1 \mathrm{~h}$ (Fig. $4 B$ ). Naive flies and flies trained with unpaired appetitive conditioning (Fig. $4 B$ and data not shown) exhibited no increase in the response to the $\mathrm{CS}^{+}$. This illustrates that a single session of appetitive conditioning generates a late-forming memory trace in the $\alpha / \beta$ MBNs, similar to that observed when flies were trained with spaced, aversive conditioning (Fig. $4 C, D$ ). These results are strikingly similar to results obtained using mammalian systems (Frankland et al., 2004) in which the retrieval of recent memories preferentially activated the hippocampal region of the brain; in 
A

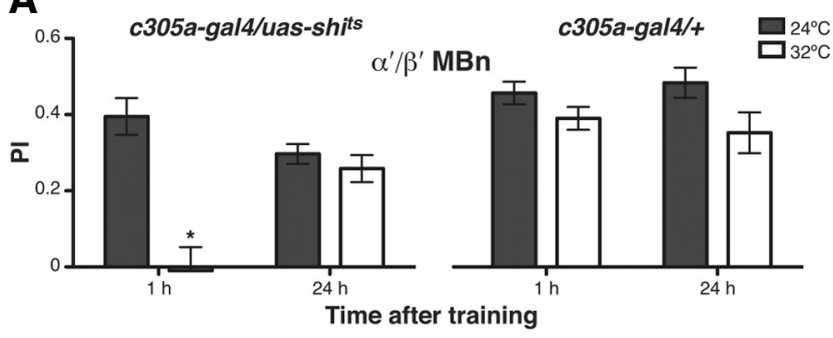

B

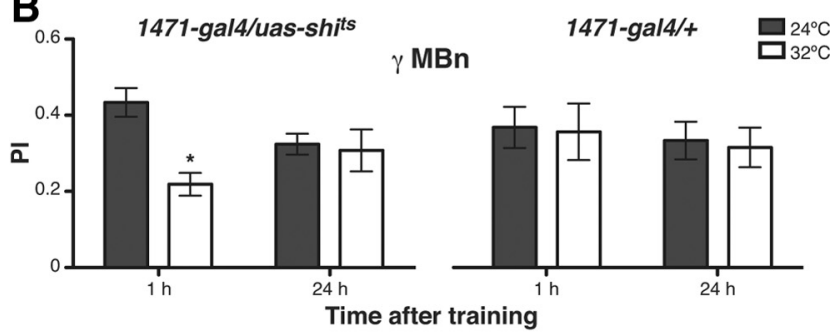

C
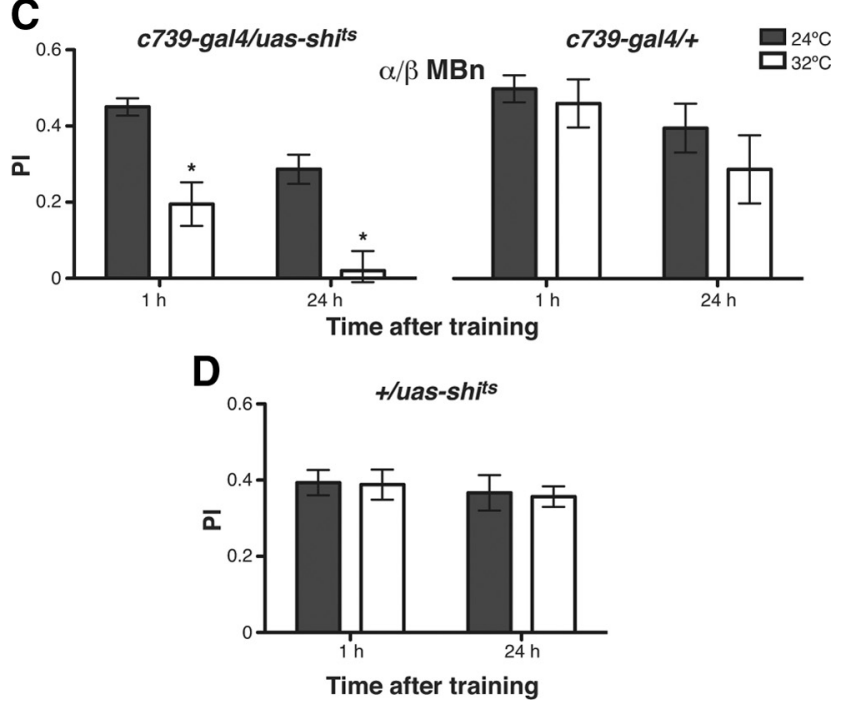

Figure 3. Time requirements for synaptic output from MBN subsets for the retrieval of appetitive olfactory memory is odor independent. $A$, All flies were conditioned using an appetitive unconditioned stimulus at $24^{\circ} \mathrm{C}$ and shifted to $32^{\circ} \mathrm{C} 10 \mathrm{~min}$ before a retrieval test. Conditioned odors used were Ben and Mes. A synaptic blockade imposed by the expression and activation of shits in the $\alpha^{\prime} / \beta^{\prime}$ MBNs significantly reduced memory expression at $1 \mathrm{~h}$ but not $24 \mathrm{~h}$ after training (Mann-Whitney pairwise comparisons, $p=0.0022$ and $p=0.3776$, respectively). № significant difference was observed between permissive and restrictive temperatures for control flies carrying only the c305a-gal4 element (Mann-Whitney pairwise comparisons, $p \geq$ 0.0649). B. Synaptic blockade of $\gamma$ MBNs significantly reduced $1 \mathrm{~h}$ but not $24 \mathrm{~h}$ appetitive olfactory memory expression (Mann-Whitney pairwise comparison, $p=0.0135$ and $p=$ 0.6304 , respectively). No significant difference was observed between permissive and restrictive temperatures for control flies carrying only the 1471-gal4 element (Mann-Whitney pairwise comparisons, $p \geq 0.7483$ ). C, Synaptic blockade of $\alpha / \beta$ MBNs significantly reduced appetitive olfactory memory expression during retrieval at 1 and $24 \mathrm{~h}$ after training (MannWhitney pairwise comparisons, $p \leq 0.0081$ ). No significant difference was observed between permissive and restrictive temperatures for control flies carrying only the 7339 -gal 4 element (Mann-Whitney pairwise comparisons, $p \geq 0.4848$ ). D, No significant difference was observed between permissive and restrictive temperatures for control flies carrying only the uas-shis ${ }^{\text {ts }}$ element (Mann-Whitney pairwise comparisons, $p \geq 0.8182$ ). Asterisks indicate a statistically significant difference assessed by Kruskal-Wallis analysis followed by Mann-Whitney pairwise comparison ( $n=6$ for each group).

contrast, no activation of this region was observed when a remote memory was retrieved (Fig. $4 E$ ). In contrast, the retrieval of remote but not recent memories was accompanied by an activation of cortical regions (Fig. $4 F$ ).
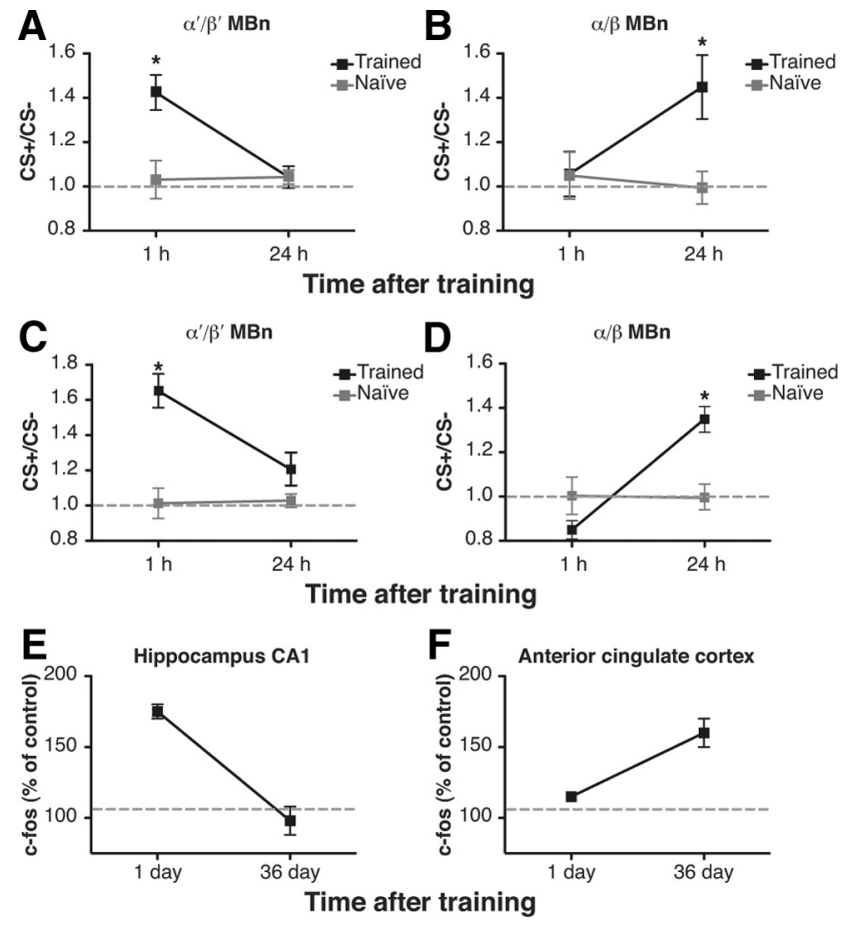

Figure 4. Retrieval of short- and long-term appetitive and aversive memories induces an increased retrieval signal to the learned odor in different MBN subsets. $\boldsymbol{A}$, Response ratio of the $\mathrm{CS}^{+} / \mathrm{CS}^{-}$as a function of time measured in the vertical branch of the $\alpha^{\prime} / \beta^{\prime}$ MBNs after appetitive olfactory conditioning and in naive flies. A robust increase in calcium influx was detected in the vertical branch during the retrieval of $1 \mathrm{~h}$ appetitive memory (Mann-Whitney pairwise comparison, $p=0.0041$ ). This increase was not detected during the retrieval of the appetitive memory $24 \mathrm{~h}$ after training (Mann-Whitney pairwise comparison, $p=0.8361$ ). No change was observed at either time point in naive animals. Asterisks indicate a statistically significant difference compared with the naive group. $n=10-16$ for each group. $\boldsymbol{B}$, Response ratio of the $\mathrm{CS}^{+} / \mathrm{CS}^{-}$as a function of time measured in the vertical branch of the $\alpha / \beta$ MBNs after appetitive olfactory conditioning and in naive flies. A robust increase in calcium influx was detected in the vertical branch during the retrieval of $24 \mathrm{~h}$ appetitive memory (Mann-Whitney pairwise comparison, $p=0.0183$ ). This increase was not detected during the retrieval of the appetitive memory $1 \mathrm{~h}$ after training (Mann-Whitney pairwise comparison, $p=1$ ). No change was observed at either time point in naive animals. Asterisks indicate a statistically significant difference compared with the naive group ( $n=10-16$ for each group). C, Response ratio of the $\mathrm{CS}^{+} / \mathrm{CS}^{-}$as a function of time measured in the vertical branch of the $\alpha^{\prime} / \beta^{\prime}$ MBNs after aversive olfactory conditioning and in naive flies. A robust increase in calcium influx was detected in the vertical branch during the retrieval of $1 \mathrm{~h}$ aversive memory (MannWhitney pairwise comparison, $p=0.0011$ ). This increase was not detected during the retrieval of the aversive memory $24 \mathrm{~h}$ after training (Mann-Whitney pairwise comparison, $p=0.2618)$. No change was observed at either time point in naive animals. Asterisks indicate a statistically significant difference compared with the naive group ( $n=10-16$ for each group). $\boldsymbol{D}$, Response ratio of the $C S^{+} / C S^{-}$as a function of time measured in the vertical branch of the $\alpha / \beta \mathrm{MBNs}$ after aversive olfactory conditioning and in naive flies. A robust increase in calcium influx was detected in the vertical branch during the retrieval of $24 \mathrm{~h}$ aversive memory (Mann-Whitney pairwise comparison, $p=0.0027$ ). This increase was not detected during the retrieval of the aversive memory $1 \mathrm{~h}$ after training (MannWhitney pairwise comparison, $p=0.2225$ ). No change was observed at either time point in naive animals. Asterisks indicate a statistically significant difference compared with the naive group ( $n=10-16$ for each group). $\boldsymbol{E}$, Expression of the activity-dependent gene $c$-fos in the hippocampus $\mathrm{CA} 1$ region after recent and remote memory tests for contextual fear conditioning in mice. c-fos expression is shown as a percentage relative to controls that were not given foot shock. Figure is adapted with permission from Frankland et al. (2004). $\boldsymbol{F}$, Expression of the activity-dependent gene $c$-fos in the anterior cingulate cortex after recent and remote memory tests for contextual fear conditioning in mice. c-fos expression is shown as a percentage relative to controls that were not given footshock. Figure is adapted with permission from Frankland et al. (2004). 
A

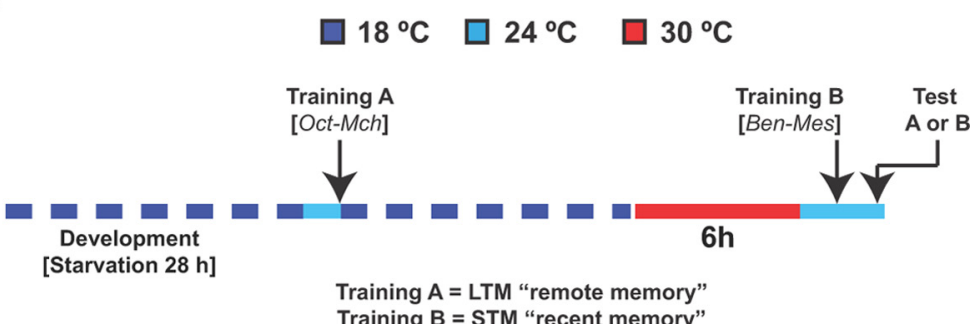

B
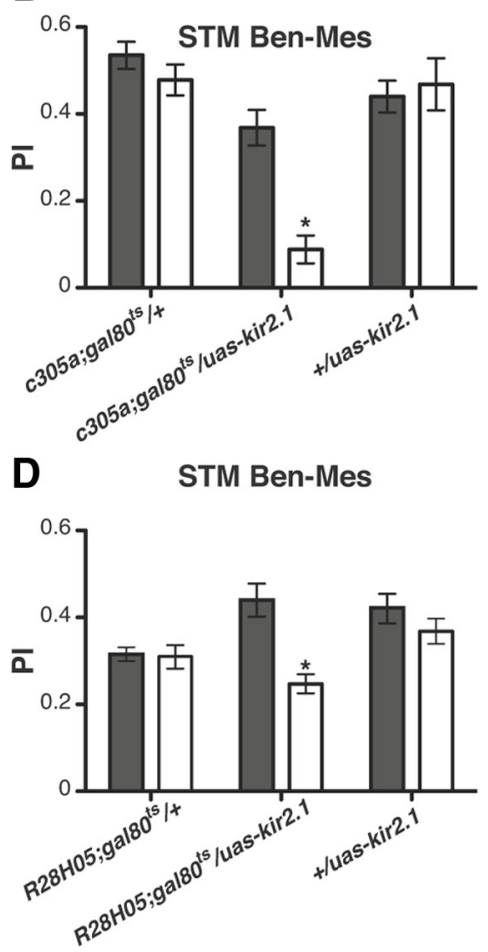

C

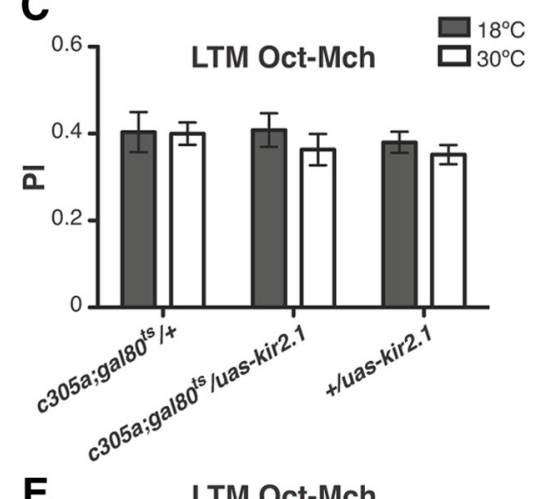

E

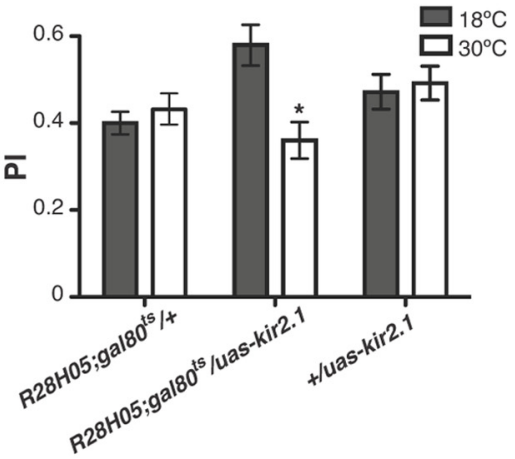

$\mathbf{F}$

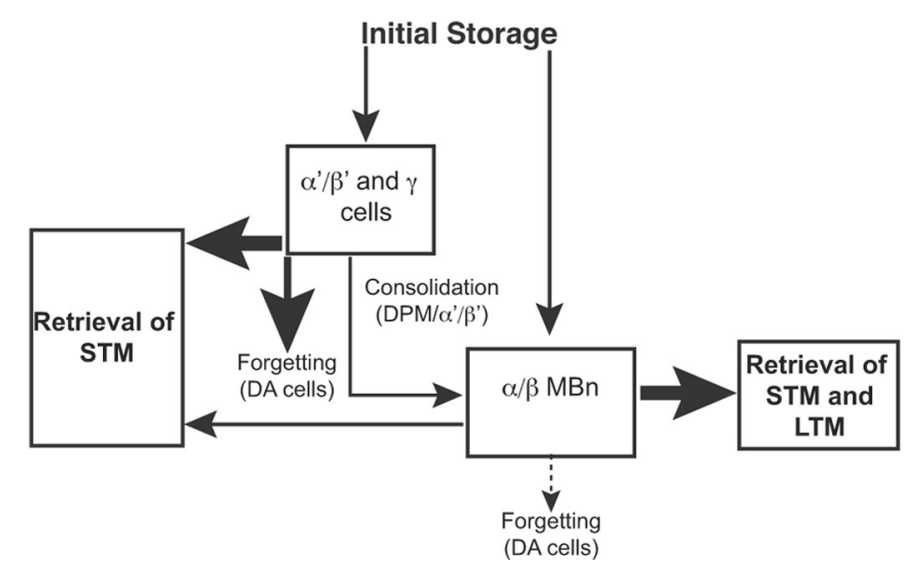

Figure 5. Disruption of $\alpha^{\prime} / \beta^{\prime}$ MBNs impairs new memories while leaving remote memories in the same animal intact. $\boldsymbol{A}$, Diagram illustrating the appetitive conditioning protocol used in this experiment. Flies carrying one copy of c305a-gal4, tubgal $80^{\text {ts }}$, and uas-kir 2.1 were raised and then starved at $18^{\circ} \mathrm{C}$ for $28 \mathrm{~h}$. Flies were then trained using forward appetitive olfactory conditioning with $0 \mathrm{ct}$ and $\mathrm{Mch}$ at $24^{\circ} \mathrm{C}$ (training A). They were fed immediately after training for $12 \mathrm{~h}$ and then starved again for $12 \mathrm{~h}$ before training $\mathrm{B}$ at $24^{\circ} \mathrm{C}$ with a second odor combination, Ben and Mes. They were then tested for memory of the first odor combination or the second. The experimental group was incubated at $30^{\circ} \mathrm{C}$ for $6 \mathrm{~h}$ before the second training experience to allow the expression of Kir2.1 and the silencing of the $\alpha^{\prime} / \beta^{\prime}$ MBNs. The control group was kept at $18^{\circ} \mathrm{C}$ during this $6 \mathrm{~h}$ incubation period. $B$, Inactivating the $\alpha^{\prime} / \beta^{\prime}$ MBNs severely impaired expression of "recent" memory (training B) (Mann-Whitney pairwise comparison, $p \leq 0.0022)$. Flies containing only $305 a-g a l 4 ; g a l 80^{\text {ts }}$, or uas-kir2.1 exhibited unaltered expression of memory from training $B$ (Mann-Whitney pairwise comparisons, $p \geq 0.6304)$. Asterisks indicate a statistically significant difference $(n=6$ for each group). C, Inactivating the $\alpha^{\prime} / \beta^{\prime}$ MBNs had no significant effect on the expression of "remote" memory (training A; Mann-Whitney

Disrupting $\boldsymbol{\alpha}^{\prime} / \boldsymbol{\beta}^{\prime}$ MBNs impairs recent but spares remote memories

The data above indicate a time-limited role for the $\alpha^{\prime} / \beta^{\prime} \mathrm{MBNs}$ in olfactory memory processing, whereas the $\alpha / \beta$ MBNs have a clear role in retrieval across all time points (Figs. 1, 2, 3, 4). To test the time-limited role for the $\alpha^{\prime} / \beta^{\prime}$ MBNs definitively, we used a novel training paradigm in which flies were trained to have both early and remote memories using two different odor pairs. This experiment is analogous to hippocampal lesioning experiments in mammals in which animals were trained to bear both recent and remote memories and the impact of hippocampal lesions was evaluated in the retrieval of both memories. We used the Kir2.1 inward-rectifying potassium channel (Baines et al., 2001) to conditionally silence the activity of $\alpha^{\prime} / \beta^{\prime}$ MBNs or $\alpha / \beta$ $\mathrm{MBNs}$ and then measured the capacity of these flies to retrieve a memory learned before the disruption ("remote memory") and a memory learned shortly after disruption ("recent memory") (Fig. 5A). To control the expression of kir2.1, we used the TARGET system: a ubiquitously expressed gal $^{\text {ts }}{ }^{\text {ts }}$ transgene that represses the expression of the channel at $18^{\circ} \mathrm{C}$ but permits expression at $30^{\circ} \mathrm{C}$ (McGuire et al., 2003). We used the Kir2.1 channel for these inactivation experiments, along with the TARGET system to produce an inactivation effect that is more permanent than can be achieved with the rapid inactivation and reversal obtained using $s h i^{\text {ts }}$.

$\leftarrow$

pairwise comparison, $p=0.6298)$. Flies containing only c305a-gal4; gal80 ${ }^{\text {ts }}$ or uas-kir2.1 exhibited unaltered expression of memory from training A (Mann-Whitney pairwise comparisons, $p \geq 0.2607)$. Asterisks indicate a statistically significant difference ( $n=6$ for each group). $\boldsymbol{D}$, Inactivating the $\alpha / \beta$ MBNs impaired expression of "recent" memory (training B; Mann-Whitney pairwise comparison, $p=$ $0.0159)$. Flies containing only $228 \mathrm{HO} 05$-gal4; gal $80^{\text {ts }}$ or uaskir2.1 exhibited unaltered expression of memory from training $B$ (Mann-Whitney pairwise comparisons, $p \geq 0.2971$ ). Asterisks indicate a statistically significant difference $(n=6$ for each group). $\boldsymbol{E}$, Inactivating the $\alpha / \beta$ MBNs significantly impaired the expression of "remote" memory (training A; MannWhitney pairwise comparison, $p=0.0129$ ). Flies containing only R28H05-gal4;gal80 ${ }^{\text {ts }}$ or uas-kir2.1 exhibited unaltered expression of memory from training A (Mann-Whitney pairwise comparisons, $p \geq 0.2403$ ). Asterisks indicate a statistically significant difference ( $n=6$ for each group). $\boldsymbol{F}$, Drosophila-adapted, standard model of system consolidation. STM is encoded in all three classes of MBNs. During system consolidation, memory traces are shifted from the three classes of MBNs so that LTM becomes the exclusive property of the $\alpha / \beta$ MBNs. The consolidation process is mediated in part by the dorsal paired medial (DPM) neurons. Dopaminergic neurons (DA) carry out active forgetting from all sets of neurons. 
We first determined the minimum time required for Kir2.1 under the dual control of gal4/gal $80^{\text {ts }}$ to exert effects using the pan-neuronal driver $c 155$-gal4. Flies containing one of two versions of uas-kir2.1, tubP-gal80 ${ }^{\text {ts }}$, and c155-gal4 were reared at $18^{\circ} \mathrm{C}$ and, $2 \mathrm{~d}$ after hatching, were transferred to $30^{\circ} \mathrm{C}$ and monitored every hour for complete paralysis. Flies carrying uas-kir2.1 on the second chromosome became completely paralyzed within $6 \mathrm{~h}$ after the temperature switch, whereas flies carrying the third chromosomal insertion required $12 \mathrm{~h}$ for complete paralysis (data not shown). The effect of expressing Kir2.1 under these conditions was irreversible. Given its greater potency, subsequent experiments were performed using the second chromosomal uas-Kir2.1 insertion.

Experimental flies were constructed to contain uas-kir2.1,

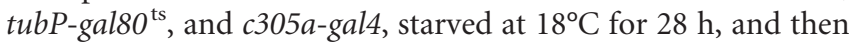
trained using olfactory appetitive conditioning with Oct and Mch as the $\mathrm{CS}^{+}$and $\mathrm{CS}^{-}$odors for measuring LTM (Fig. $5 \mathrm{~A}$, training A, "remote memory"). They were then refed, restarved, and trained again with Ben and Mes as the $\mathrm{CS}^{+}$and $\mathrm{CS}^{-}$odors for measuring STM (Fig. 5A, training B, "recent memory"). The experimental group was transferred to $30^{\circ} \mathrm{C}$ at $6 \mathrm{~h}$ before the second training experience, whereas the control group was kept at $18^{\circ} \mathrm{C}$ throughout the experiment. Silencing the $\alpha^{\prime} / \beta^{\prime}$ MBNs $6 \mathrm{~h}$ prior to the second training episode completely disrupted the expression of recent memory, whereas this silencing had no detectable effect on remote memory (Fig. $5 B, C$ ). The control flies containing only the uas-kir 2.1 or gal4 tubP-galso ${ }^{\text {ts }}$ genetic elements were able to display both remote and recent memories, with no apparent retroactive or proactive interference detected (Fig. $5 B, C$ ). These data indicate that newly formed memories require the function of the $\alpha^{\prime} / \beta^{\prime}$ MBNs, but that remote memories are independent of this function.

Pilot experiments performed for the complementary experiment demonstrated that expressing uas-kir2.1 using the c739gal4 driver resulted in paralysis/lethality, presumably due to expression of the c739-gal4 driver in regions other than the $\alpha / \beta$ MBNs. To circumvent this problem, we used a more specific gal4 driver, $\mathrm{R} 28 \mathrm{H05}$-gal4, which exhibits expression in most, but not all, $\alpha / \beta$ MBNs (Jenett et al., 2012). As expected, silencing the $\alpha / \beta$ MBNs $6 \mathrm{~h}$ prior to the second training episode impaired the expression of recent memories (Fig. 5D). Similarly, silencing $\alpha / \beta$ MBNs with Kir2.1 significantly impaired the retrieval of remote memories (Fig. 5E). The impairment of both recent and remote memory retrieval was expected, given this durable disruption, but the incomplete impairment was not anticipated. The incomplete impairment is presumably the result of differences in $\alpha / \beta$ MBNs coverage by the $c 739$-gal4 versus the $\mathrm{R} 28 \mathrm{H05}$-gal4 drivers (Jenett et al., 2012). Control flies carrying only the uas-kir2.1 or gal4 tubP-gal80 ${ }^{\text {ts }}$ genetic elements exhibited robust retrieval of both remote and recent memories (Fig. $5 D, E$ ). These data indicate that the retrieval of both newly formed and remote memories requires the function of the $\alpha / \beta$ MBNs.

\section{Discussion}

We present here an extensive set of experiments using transient synaptic blockade, functional cellular imaging, and cellular inactivation to probe the role of different sets of MBNs on memory expression at multiple time points after the acquisition of appetitive or aversive olfactory memories. We found that the expression of appetitive and aversive olfactory memories follow the same general rules: they are dependent on synaptic transmission from the $\alpha^{\prime} / \beta^{\prime}, \alpha / \beta$, and $\gamma$ MBNs for a few hours after conditioning, but become independent of $\alpha^{\prime} / \beta^{\prime}$ and $\gamma$ MBNs and com- pletely dependent on $\alpha / \beta$ MBNs for the expression of memories at $24 \mathrm{~h}$. These observations led us to offer the hypothesis that olfactory memories in Drosophila are processed in system consolidation manner.

At least three lines of evidence before this study were consistent with the hypothesis that olfactory memories generated by classical conditioning of Drosophila undergo system consolidation. First, disrupting the synaptic function of $\gamma \mathrm{MBNs}$ during retrieval of appetitive memory at $2 \mathrm{~h}$ after training impairs performance (recent memory), but has no effect on retrieval when the disruption is applied at $24 \mathrm{~h}$. In contrast, disrupting synaptic function of the $\alpha / \beta$ MBNs during retrieval at $2 \mathrm{~h}$ after training was reported to be without apparent effect on performance at this time point, but impairs retrieval of remote memory when the disruption is applied at $24 \mathrm{~h}$ (Trannoy et al., 2011). These observations suggest that the $\gamma$ MBNs participate in processes underlying recent appetitive memories, whereas the $\alpha / \beta$ MBNs participate in processes underlying remote appetitive memories. The role of other possible participants-the $\alpha^{\prime} / \beta^{\prime}$ neurons in particular-was not investigated in this study nor were retrieval disruptions earlier than $2 \mathrm{~h}$ after conditioning tested. A possible role of the $\alpha^{\prime} / \beta^{\prime}$ neurons in system consolidation is important to consider because similar disruptions in synaptic transmission during or after conditioning disrupts recent $(3 \mathrm{~h}$ ) memory (Krashes et al., 2007).

Second, the STM deficit of the rutabaga (rut, calciumdependent adenylyl cyclase) mutant in aversive memory can be partially rescued by expression of a rut wild-type transgene in $\gamma$ MBNs, whereas the LTM deficit is partially rescued with expression in $\alpha / \beta \mathrm{MB}$ cells (Zars et al., 2000; Akalal et al., 2006; Blum et al., 2009; Trannoy et al., 2011; Qin et al., 2012). These observations indicate that rut function is required in one set of neurons for recent memories, and in another set for remote memories.

Third, imaging studies indicate that retrieval of STM and LTM activates different regions of the Drosophila brain. For example, the retrieval of LTM after aversive training activates $\alpha / \beta$ MBNs (Yu et al., 2006; Akalal et al., 2011), whereas retrieval of STM activates $\alpha^{\prime} / \beta^{\prime}$ MBNs (Wang et al., 2008) and antennal lobe projection neurons (Yu et al., 2004). Functional imaging experiments have also revealed a LTM trace in the $\gamma$ lobes that is exposed by retrieval (Akalal et al., 2010), but no STM traces have been discovered in these neurons despite their consistent implication in STM processes.

Despite these hints, there are discrepancies in the data between studies and the complete set of data necessary to draw firm conclusions have been lacking. For example, rut rescue experiments (Akalal et al., 2006; Blum et al., 2009) reveal a requirement for rut function for STM and LTM in different sets of neurons, showing that this genetic function is somehow important for processing memory in these two sets of neurons, but they do not directly address whether the responsibility for storing a particular memory shifts between the two regions. In addition, experiments to disrupt synaptic function acutely are usually performed during or early after conditioning, with retrieval measured hours after the acute disruption is removed. Such experiments reveal a role for synaptic activity of the disrupted neurons for the formation of the memory tested much later, but do not clearly define the temporal window for when neuronal activity is required, nor do they reveal where memories are stored, which is best assessed through disruption experiments at the time of retrieval.

Three lines of evidence presented here argue that both aversive and appetitive olfactory memories in Drosophila are processed using system consolidation processing. First, we showed that memories that are initially dependent on synaptic transmis- 
sion of $\alpha^{\prime} / \beta^{\prime}$ and $\gamma \mathrm{MBNs}$ become independent of these neurons with time. The time course for gaining independence for the two sets of neurons is similar (Fig. 1, Fig. 2), which is consistent with the possibility that they cooperate in the formation and storage of early memories (Fig. 5D). The $\alpha / \beta \mathrm{MBNs}$ are also partially required for the retrieval of STM/ITM, with LTM becoming completely dependent on this subset of MBNs. These observations are consistent with the system consolidation of memories from the $\alpha^{\prime} / \beta^{\prime} / \gamma$ MBNs to the $\alpha / \beta$ MBNs (Fig. 5D). Second, we showed by functional imaging that $\alpha^{\prime} / \beta^{\prime}$ MBNs express an increased calcium response to a retrieval cue for both aversive and appetitive olfactory STM/ITM, but not LTM. In contrast, the retrieval of LTM, but not STM/ITM, produces an increased response in the $\alpha / \beta$ MBNs. These results echo the transfer of altered responses observed between the hippocampus and neocortex (Fig. 4) due to the system consolidation reorganization of the brain circuitry underlying different phases of memories (Bontempi et al., 1999; Frankland et al., 2004; Maviel et al., 2004). Finally, the most definitive demonstration of system consolidation was performed by measuring "early" and "remote" memories in the same genotype of flies after inactivation of specific brain regions. We demonstrated that STM and LTM to two different odor pairs can coexist in the brain of the fly without any obvious interference and that the $\alpha^{\prime} / \beta^{\prime}$ MBNs perform a transient role in the formation and retrieval of new memories and are apparently without a function for retrieval of LTM. These results support the idea that olfactory memories in Drosophila are processed by system consolidation.

One proposition for how different sets of neurons in the olfactory pathway underlie different temporal forms of memory is that parallel and fully independent traces form for STM and LTM after conditioning, with a trace for STM forming in the $\gamma$ MBNs and a LTM trace forming in the $\alpha / \beta$ MBNs (Trannoy et al., 2011). In this proposition, cellular consolidation within the $\alpha / \beta \mathrm{MBNs}$ would play an exclusive role for solidifying LTM, with no need for interactions between the $\gamma$ MBNs and $\alpha / \beta$ MBNs. However, other neurons need to be considered beyond these two types, because it has been reported that $\alpha^{\prime} / \beta^{\prime}$ and DPM neuron function is required during the time window of consolidation for the expression of ITM and LTM (Yu et al., 2006; Krashes et al., 2007; Krashes and Waddell, 2008). Similarly, it was recently shown that blocking synaptic output of $\alpha / \beta$ MBNs $6 \mathrm{~h}$ after training also impairs LTM expression (Huang et al., 2012). The latter data are inconsistent with a model in which olfactory memories are processed by completely independent parallel traces. The data we provide here, along with those from selected prior studies, point to system consolidation: STM is guided by memory traces that form in the $\alpha^{\prime} / \beta^{\prime}, \alpha / \beta$, and $\gamma \mathrm{MBNs}$, with synaptic interactions occurring between $\alpha^{\prime} / \beta^{\prime}$ MBNs (and perhaps $\gamma$ MBNs) with $\alpha / \beta$ MBNs that guides the evolution of a LTM trace in the $\alpha / \beta$ MBNs.

Our Drosophila-adapted version for the standard model of system consolidation (Dudai, 2004) is presented in Figure 5F. For simplicity, this model emphasizes the roles for the three different, well established subsets of MBNs, although further subdivision of function is conceivable (Huang et al., 2012) and other neuron types may be added with future studies (Chen et al., 2012). Initial encoding occurs in all three subsets of MBNs. With time, consolidation reinforces the $\alpha / \beta$ memory trace, whereas STM/ITM traces in the $\alpha^{\prime} / \beta^{\prime}$ and $\gamma$ MBNs decay, perhaps partly through dopamine-dependent forgetting mechanisms (Berry et al., 2012). The $\alpha^{\prime} / \beta^{\prime}-\gamma$ memory traces contribute to the retrieval of STM/ ITM. With time, the retrieval of LTM becomes completely independent of $\alpha^{\prime} / \beta^{\prime}$ and $\gamma$, with $\alpha / \beta$ emerging as the major player in driving the learned behavior.
There are differences to be noted between the standard model for system consolidation in mammals (Dudai, 2004) and our Drosophila adapted version (Fig. 5D). The most apparent is that the mammalian model is based on recent and remote memories that are both protein-synthesis dependent, whereas the STM in Drosophila assayed here is protein-synthesis independent. Nevertheless, the model for system consolidation processing of olfactory memories in Drosophila uses the same principles of interaction and reorganization between brain circuits, with early and late memories being supported by different brain regions.

\section{References}

Akalal DB, Wilson CF, Zong L, Tanaka NK, Ito K, Davis RL (2006) Roles for Drosophila mushroom body neurons in olfactory learning and memory. Learn Mem 13:659-668. CrossRef Medline

Akalal DB, Yu D, Davis RL (2010) A late-phase, long-term memory trace forms in the $\gamma$ neurons of Drosophila mushroom bodies after olfactory classical conditioning. J Neurosci 30:16699-16708. CrossRef Medline

Akalal DB, Yu D, Davis RL (2011) The long-term memory trace formed in the Drosophila $\alpha / \beta$ mushroom body neurons is abolished in long-term memory mutants. J Neurosci 31:5643-5647. CrossRef Medline

Aso Y, Grübel K, Busch S, Friedrich AB, Siwanowicz I, Tanimoto H (2009) The mushroom body of adult Drosophila characterized by GAL4 drivers. J Neurogenet 23:156-172. CrossRef Medline

Baines RA, Uhler JP, Thompson A, Sweeney ST, Bate M (2001) Altered electrical properties in Drosophila neurons developing without synaptic transmission. J Neurosci 21:1523-1531. Medline

Berry J, Cervantes-Sandoval I, Nicholas EP, Davis RL (2012) Dopamine is required for learning and forgetting in Drosophila. Neuron 74:530-542. CrossRef Medline

Blum AL, Li W, Cressy M, Dubnau J (2009) Short- and long-term memory in Drosophila require cAMP signaling in distinct neuron types. Curr Biol 19:1341-1350. CrossRef Medline

Bontempi B, Laurent-Demir C, Destrade C, Jaffard R (1999) Timedependent reorganization of brain circuitry underlying long-term memory storage. Nature 400:671-675. CrossRef Medline

Carew TJ, Pinsker HM, Kandel ER (1972) Long-term habituation of a defensive withdrawal reflex in Aplysia. Science 175:451-454. CrossRef Medline

Cervantes-Sandoval I, Davis RL (2012) Distinct traces for appetitive versus aversive olfactory memories in DPM neurons of Drosophila. Curr Biol 22:1247-1252. CrossRef Medline

Chen CC, Wu JK, Lin HW, Pai TP, Fu TF, Wu CL, Tully T, Chiang AS (2012) Visualizing long-term memory formation in two neurons of the Drosophila brain. Science 335:678-685. CrossRef Medline

Cho YH, Beracochea D, Jaffard R (1993) Extended temporal gradient for the retrograde and anterograde amnesia produced by ibotenate entorhinal cortex lesions in mice. J Neurosci 13:1759-1766. Medline

Clark RE, Broadbent NJ, Zola SM, Squire LR (2002) Anterograde amnesia and temporally graded retrograde amnesia for a nonspatial memory task after lesions of hippocampus and subiculum. J Neurosci 22:4663-4669. Medline

Colomb J, Kaiser L, Chabaud MA, Preat T (2009) Parametric and genetic analysis of Drosophila appetitive long-term memory and sugar motivation. Genes Brain Behav 8:407-415. CrossRef Medline

Dubnau J, Grady L, Kitamoto T, Tully T (2001) Disruption of neurotransmission in Drosophila mushroom body blocks retrieval but not acquisition of memory. Nature 411:476-480. CrossRef Medline

Dudai Y (2004) The neurobiology of consolidations, or, how stable is the engram? Annu Rev Psychol 55:51-86. CrossRef Medline

Frankland PW, Bontempi B (2005) The organization of recent and remote memories. Nat Rev Neurosci 6:119-130. CrossRef Medline

Frankland PW, Bontempi B, Talton LE, Kaczmarek L, Silva AJ (2004) The involvement of the anterior cingulate cortex in remote contextual fear memory. Science 304:881-883. CrossRef Medline

Huang C, Zheng X, Zhao H, Li M, Wang P, Xie Z, Wang L, Zhong Y (2012) A permissive role of mushroom body $\alpha / \beta$ core neurons in long-term memory consolidation in Drosophila. Curr Biol 22:1981-1989. CrossRef Medline

Isabel G, Pascual A, Preat T (2004) Exclusive consolidated memory phases in Drosophila. Science 304:1024-1027. CrossRef Medline 
Jenett A, Rubin GM, Ngo TT, Shepherd D, Murphy C, Dionne H, Pfeiffer BD, Cavallaro A, Hall D, Jeter J, Iyer N, Fetter D, Hausenfluck JH, Peng H, Trautman ET, Svirskas RR, Myers EW, Iwinski ZR, Aso Y, DePasquale GM, et al. (2012) A GAL4-driver line resource for Drosophila neurobiology. Cell Rep 2:991-1001. CrossRef Medline

Kapur N, Brooks DJ (1999) Temporally-specific retrograde amnesia in two cases of discrete bilateral hippocampal pathology. Hippocampus 9:247254. CrossRef Medline

Kitamoto T (2001) Conditional modification of behavior in Drosophila by targeted expression of a temperature-sensitive shibire allele in defined neurons. J neurobiol 47:81-92. CrossRef Medline

Krashes MJ, Waddell S (2008) Rapid consolidation to a radish and protein synthesis-dependent long-term memory after single-session appetitive olfactory conditioning in Drosophila. J Neurosci 28:3103-3113. CrossRef Medline

Krashes MJ, Keene AC, Leung B, Armstrong JD, Waddell S (2007) Sequential use of mushroom body neuron subsets during Drosophila odor memory processing. Neuron 53:103-115. CrossRef Medline

Manns JR, Hopkins RO, Squire LR (2003) Semantic memory and the human hippocampus. Neuron 38:127-133. CrossRef Medline

Maviel T, Durkin TP, Menzaghi F, Bontempi B (2004) Sites of neocortical reorganization critical for remote spatial memory. Science 305:96-99. CrossRef Medline

McGaugh JL, Alpern HP (1966) Effects of electroshock on memory: amnesia without convulsions. Science 152:665-666. CrossRef Medline

McGuire SE, Le PT, Davis RL (2001) The role of Drosophila mushroom body signaling in olfactory memory. Science 293:1330-1333. CrossRef Medline

McGuire SE, Le PT, Osborn AJ, Matsumoto K, Davis RL (2003) Spatiotemporal rescue of memory dysfunction in Drosophila. Science 302: 1765-1768. CrossRef Medline

Qin H, Cressy M, Li W, Coravos JS, Izzi SA, Dubnau J (2012) Gamma neurons mediate dopaminergic input during aversive olfactory memory formation in Drosophila. Curr Biol 22:608-614. CrossRef Medline

Quinn WG, Dudai Y (1976) Memory phases in Drosophila. Nature 262: 576-577. CrossRef Medline

Scoville W, Milner B (1957) Loss of recent memory after bilateral hippocampal lesions. J Neurol Neurosurg Psychiatr 20:11-21. CrossRef Medline

Squire LR, Slater PC, Chace PM (1975) Retrograde amnesia: temporal gradient in very long term memory following electroconvulsive therapy. Science 187:77-79. CrossRef Medline

Tempel BL, Bonini N, Dawson DR, Quinn WG (1983) Reward learning in normal and mutant Drosophila. Proc Natl Acad Sci U S A 80:1482-1486. CrossRef Medline

Tian L, Hires SA, Mao T, Huber D, Chiappe ME, Chalasani SH, Petreanu L, Akerboom J, McKinney SA, Schreiter ER, Bargmann CI, Jayaraman V, Svoboda K, Looger LL (2009) Imaging neural activity in worms, flies and mice with improved GCaMP calcium indicators. Nat Methods 6:875881. CrossRef Medline

Trannoy S, Redt-Clouet C, Dura JM, Preat T (2011) Parallel processing of appetitive short- and long-term memories in Drosophila. Curr Biol 21: 1647-1653. CrossRef Medline

Tully T, Quinn WG (1985) Classical conditioning and retention in normal and mutant Drosophila melanogaster. J Comp Physiol A 157:263-277. CrossRef Medline

Tully T, Preat T, Boynton SC, Del Vecchio M (1994) Genetic dissection of consolidated memory in Drosophila. Cell 79:35-47. CrossRef Medline

Turner GC, Bazhenov M, Laurent G (2008) Olfactory representations by Drosophila mushroom body neurons. J Neurophysiol 99:734-746. CrossRef Medline

Waddell S, Armstrong JD, Kitamoto T, Kaiser K, Quinn WG (2000) The amnesiac gene product is expressed in two neurons in the Drosophila brain that are critical for memory. Cell 103:805-813. CrossRef Medline

Wang Y, Chiang AS, Xia S, Kitamoto T, Tully T, Zhong Y (2003) Blockade of neurotransmission in Drosophila mushroom bodies impairs odor attraction, but not repulsion. Curr Biol 13:1900-1904. CrossRef Medline

Wang Y, Mamiya A, Chiang AS, Zhong Y (2008) Imaging of an early memory trace in the Drosophila mushroom body. J Neurosci 28:4368-4376. CrossRef Medline

Yu D, Ponomarev A, Davis RL (2004) Altered representation of the spatial code for odors after olfactory classical conditioning; memory trace formation by synaptic recruitment. Neuron 42:437-449. CrossRef Medline

Yu D, Keene AC, Srivatsan A, Waddell S, Davis RL (2005) Drosophila DPM neurons form a delayed and branch-specific memory trace after olfactory classical conditioning. Cell 123:945-957. CrossRef Medline

Yu D, Akalal DB, Davis RL (2006) Drosophila $\alpha / \beta$ mushroom body neurons form a branch-specific, long-term cellular memory trace after spaced olfactory conditioning. Neuron 52:845-855. CrossRef Medline

Zars T, Fischer M, Schulz R, Heisenberg M (2000) Localization of a shortterm memory in Drosophila. Science 288:672-675. CrossRef Medline

Zhang S, Yin Y, Lu H, Guo A (2008) Increased dopaminergic signaling impairs aversive olfactory memory retention in Drosophila. Biochem Biophys Res Commun 370:82-86. CrossRef Medline

Zola-Morgan SM, Squire LR (1990) The primate hippocampal formation: evidence for a time-limited role in memory storage. Science 250:288-290. CrossRef Medline 